УДК 349.2:342

DOI https://doi.org/10.17308/vsu.proc.law.2021.1/3269

\title{
ОБ УЧАСТИИ ПРЕДСТАВИТЕЛЕЙ РАБОТНИКОВ В УПРАВЛЕНИИ ОРГАНИЗАЦИЕЙ В РОССИИ: ИСТОРИЧЕСКИЙ АСПЕКТ
}

\author{
А. С. Кудрин \\ Перлский национальный исследовательский политехнический \\ университет, Перлский фбилиал Российской акаделии \\ народного хозяйства и государственной службы \\ при Президенте Российской Федераиии
}

Поступила в редакцию 10 августа 2020 г.

\begin{abstract}
Аннотация: рассматриваются некоторые вопросы участия представителей работников в управлении организацией в России в различные периоды истории ХХ в. Отлечается ряд особенностей участия работников в управлении организацией в соответствии с действовавшил законодательствол. Делается вывод о тол, что участие представителей работников в управлении организацией в России прошло длительную эволюиию, обусловленную историческили, политическили, социально-эконолическими фбакторами, от широкого участия до фбактически полного отсутствия в период тотального политического режила и последующего постепенного возрождения в дальнейшел.
\end{abstract}

Ключевые слова: управление организаиией, работники, трудовые отношения, социальное партнерство.

Abstract: the article is examined some issues of the participation of employee representatives in the management of organizations in different periods of the history of the 20th century. A number of features of the participation of employees in the management of the organization in accordance with the legislation in force are noted. It is concluded that the participation of employee representatives in the management of an organization in Russia has come a long evolution, due to historical, political, socio-economic factors, from wide participation to virtually complete absence during the period of a total political regime and subsequent gradual revival in the future.

Key words: organization management, workers, labour relations, social partnership.

Важно начать с того, что в России вопрос участия работников в управлении организацией имеет свою историю и свои особенности. Так, после Февральской буржуазно-демократической революции 1917 г. стихийно стали образовываться фабрично-заводские комитеты (далее - ФЗК).

По призыву Петроградского совета рабочих и солдатских депутатов 5 марта 1917 г. фобрично-заводские комитеты организовались на предприятиях Петрограда, а за ним в Москве и провинции. 10 марта 1917 г. состоялось «соглашение» Петроградского совета с обществом заводчиков

(C) Кудрин А. С., 2021 
и фрабрикантов; это «соглашение» признало возможным существование фабрично-заводских комитетов ${ }^{1}$.

Данные комитеты избирались на общих собраниях рабочими и служащими предприятия (или нескольких предприятий) и в отличие от профсоюзов в первые постреволюционные месяцы объединяли рабочих независимо от их профрсозной, партийной или профессиональной принадлежности. Главной задачей ФЗК было осуществление рабочего контроля над производством и распределением. Они самостоятельно вводили и устанавливали восьмичасовой рабочий день, решали вопросы расценок и зарплаты, приема и увольнения, снабжения рабочих продовольствием, брали на себя функции управления в том случае, если предприниматели пытались закрыть предприятие или сократить производство. Впоследствии ФЗК стали осуществлять выработку тарифов, заключение коллективных договоров, организации медицинской помощи рабочим ${ }^{2}$.

Пришедшее к власти Временное правительство не могло не отреагировать на бурную и неурегулированную с точки зрения права деятельность ФЗК. Было издано постановление Временного правительства о рабочих комитетах на промышленных предприятиях. Согласно постановлению устанавливались предметы ведения рабочих, представительство рабочих перед администрацией заведения по вопросам, касающимся внутренних взаимоотношений между предпринимателями и рабочими, как-то: о заработной плате, рабочем времени, правилах внутреннего распорядка и т. п.; разрешение вопросов, касающихся внутренних взаимоотношений между рабочими заведений; представительство рабочих в их сношениях с правительственными и общественными учреждениями; заботы о культурно-просветительной деятельности среди рабочих заведения и о других мероприятиях, направленных на улучшение их быта ${ }^{3}$.

Впоследствии советская историография называла данный правовой акт как «наступление буржуазии на права трудящихся» ${ }^{4}$

По данным Всероссийской промышленной переписи, проведенной в 1918 г., до Великой Октябрьской социалистической революции ФЗК действовали на 2151 предприятии, при этом $69 \%$ - на средних и крупных производствах ${ }^{5}$.

После Октябрьской революции 1917 г. большая часть ФЗК поддержала большевиков в борьбе за политическую и государственную власть.

1 Постановление Временного правительства о рабочих комитетах в промышленных предприятиях от 23 апреля 1917 г. URL: http://www.illuminats.ru/ component/content/article/29-new/5183--------6--1917 (дата обращения: 02.05.2020).

2 См.: Большая советская энциклопедия. URL: https://www.booksite.ru/fulltext/1/001/008/115/103.htm (дата обращения: 02.05.2020).

3 Постановление Временного правительства о рабочих комитетах в промышленных предприятиях от 23 апреля 1917 г. URL: http://www.illuminats.ru/ component/content/article/29-new/5183--------6--1917 (дата обращения: 02.05.2020).

${ }^{4}$ Там же.

${ }^{5}$ См.: Михайлов Н. В. Самоорганизация трудовых коллективов и психология российских рабочих в начале XX в. // Рабочие и интеллигенция России в эпоху реформ и революций, 1861 - февраль 1917 г. СПб., 1997. С. 153-155. 


\section{Вестник ВГУ. Серия: Право}

Вместе с тем в течение 1918 г. существовавшие ФЗК постепенно были объединены с профессиональными союзами и утратили свою самостоятельность.

В период гражданской войны и иностранной интервенции произошло введение всеобщей трудовой повинности и централизация управления всей экономикой и хозяйством, что в конечном счете вылилось в проведение политики "военного коммунизма».

В принятом и опубликованном 10 декабря 1918 г. Кодексе законов о труде РСФСР главным приоритетом в регулировании в сфере общественных отношений являлось использование механизма трудовой повинности ${ }^{6}$.

Поэтому в рассматриваемый период фрактически ни о каком реальном участии работников в управлении организацией говорить не приходится.

Интересно отметить, что профессиональные союзы, «поглотившие» ФЗК, в то время главным образом «оказывали помощь органам труда в проведении трудовой повинности, вели борьбу за поднятие производительности труда, за укрепление трудовой дисциплины, создавали дисциплинарные товарищеские суды и содействовали проведению коммунистических субботников» ${ }^{7}$.

Вместе с тем даже в большевистской среде не было единого мнения о роли объединений работников в системе управления государством и экономикой. Этот фракт обусловил возникновение в РКП(б) так называемой «рабочей оппозиции». Так, в марте 1920 г. на заседании комфракции ВЦСПС А. Г. Шляпников представил тезисы, в которых предлагал разделить функции Советов, партии и профсоюзов. Он предложил довольно простую схему: партия является ответственным политическим государственным руководителем революционной борьбы и строительства,

- Советы - формой политической власти, а профсоюзы - единственной ответственной организацией народного хозяйства и школой управления промышленностью для рабочих. Тезисы А. Г. Шляпникова вызвали сильное беспокойство ЦК РКП(б), увидевшего в них проявление в профрсозах тенденции к синдикализму и покушение на руководящую роль партии в экономике и в итоге были отвергнуты партийным большинством ${ }^{8}$.

C переходом государства к новой экономической политике (нэпу) и некоторой либерализацией общественной жизни изменилась и государственная политика в сорере труда.

В связи с этим постановлением ВЦИК от 9 ноября 1922 г. был принят Кодекс законов о труде РСФСР 1922 г. (далее - КЗоТ РСФСР 1922 г.). Оценивая принятый кодекс, В. И. Ленин полагал, что «...это громадное завоевание Советской власти, что в такое время, когда все страны

${ }^{6}$ См.: Советское трудовое право / под ред. Н. Г. Александрова. М., 1949. С. 88-89.

${ }^{7}$ Там же. С. 92.

${ }^{8}$ См.: Санду T. А. Рабочая оппозиция в РКП(б). 1920-1921 гг. URL: https:// rabkrin.org/sandu-t-a-rabochaya-oppozitsiya-v-rkp-b-1920-1921-gg-statya / (дата обращения: 02.05.2020). 
ополчаются на рабочий класс, мы выступаем с кодексом, который прочно устанавливает основы рабочего законодательства ${ }^{9}$.

Важно заметить, что глава 15 КЗоТ РСФСР 1922 г. была посвящена профрессиональным (производственным) союзам рабочих и служащих и их органам в предприятиях, учреждениях и хозяйствах. В ст. 151 кодекса отмечалось, что «профессиональные (производственные) союзы, объединяющие граждан, работающих по найму в государственных, общественных и частных предприятиях, учреждениях и хозяйствах, имеют право выступать перед различными органами от имени работающих по найму в качестве стороны, заключающей коллективные договоры, а равно представительствовать от их имени по всем вопросам труда и быта». Именно такие объединения были правомочны осуществлять представительство и защиту интересов рабочих и служащих, объединяемых ими, перед администрацией предприятия, учреждения и хозяйства, по вопросам условий труда и быта работников, представительство перед правительственными и общественными организациями, а также наблюдение за точным исполнением администрацией предприятия, учреждения или хозяйства установленных законом норм по охране труда, социальному страхованию, выплате заработной платы, правил санитарии и техники безопасности и пр.

Статья 156 кодекса предусматривала, что первичным органом профессионального союза в предприятии, учреждении или хозяйстве является комитет рабочих и служащих (фабрично-заводской, рудничный, построечный, местный и т. п.) или заменяющий комитет делегат - уполномоченный союза. Тем самым фрабрично-заводские комитеты и подобные организации оставались исключительно «в лоне» профрессиональных союзов. Кроме того, в силу ст. 157 кодекса «никакой иной комитет в предприятиях, учреждениях или хозяйствах, кроме предусмотренного ст. 156 кодекса и утвержденного соответствующим профрессиональным (производственным) союзом, не мог пользоваться правами профессионального (производственного) союза».

Следует отметить, что с конца 20-х гг. ХХ в. с провозглашением ВКП(б) курсов на индустриализацию и коллективизацию происходит централизация управления сощиально-трудовыми отношениями. Итогом данной политики в сфрере труда было включение системы профессиональных союзов в партийно-государственный аппарат с возложением на них непрофильных полномочий. «В 1933 г. был ликвидирован Народный комиссариат СССР (НКТ СССР). Все его органы, включая органы социального страхования и инспекции труда, были переданы профрсюзам и слиты с профроюзным аппаратом в центре и на местах... На единственный в стране профсоюзный орган ВЦСПС были возложены в монопольном по-

${ }^{9}$ Ленин В. И. Речь на IVсессии ВЦИК IX созыва 31 октября 1922 г. // Полн. собр. соч. : в 55 т. М., 1964. Т. 45. С. 246. 
рядке задачи государственного управления важными аспектами труда и трудовых отношений» ${ }^{10}$.

Тем самым в рассматриваемый период «монополия государства-работодателя становится абсолютной, зависимость работника - тотальной. Сверхцентрализация государственной воли, сверхрегулирование и манипулирование на этой основе приводят к массовой имитации наемного труда, видимости дела и порядка» ${ }^{11}$.

Важно заметить, что в принятых 15 июля 1970 г. Основах законодательства СССР и союзных республик о труде в ст. 97 гарантировалось право рабочих и служащих участвовать в управлении предприятиями, учреждениями, организациями. Речь шла о том, что рабочие и служащие имели право участвовать в управлении предприятиями, учреждениями, организациями через общие собрания (конференции) и советы трудовых коллективов, через профессиональные союзы и иные общественные организации, органы народного контроля и другие общественные органы, действующие в трудовых коллективах.

Аналогичная правовая норма была закреплена и в Кодексе законов о труде РСФСР 1971 г. (далее - КЗоТ РСФСР 1971 г.). В ст. 227 данного акта предусматривалось право рабочих и служащих участвовать в управлении производством, а в ст. 228 определялись фрормы такого участия - через профрессиональные союзы и иные общественные организации, органы народного контроля, общие собрания, производственные совещания, конференции и различные формы общественной самодеятельности рабочих и служащих.

Необходимо отметить, что особая роль в управлении производством, по мысли законодателя, отводилась трудовым коллективам, которые получили конституционно-правовой статус с принятием Конституции - СССР 1977 г. (далее - Конституция CССР 1977 г.). Так, в частности, ст. 8 일 данного акта предусматривала, что трудовые коллективы участвуют в обсуждении и решении государственных и общественных дел, в планировании производства и социального развития, в подготовке и расстановке кадров, в обсуждении и решении вопросов управления предприятиями и учреждениями, улучшения условий труда и быта, использования средств, предназначенных для развития производства... Аналогичная по содержанию норма закреплялась и в ст. 8 Конституции РСФСР 1978 г. и конституциях союзных республик.

Конституционные положения о трудовых коллективах содержались в главе 1 Конституции «Политическая система», что придавало рассматриваемым объединениям работников не только статус субъектов трудового права, но и субъектов политической системы государства.

Рассматривая статус трудовых коллективов в СССР Л. Ю. Бугров отмечает, что «планами нормотворческой деятельности по приведению за-

${ }^{10}$ Киселев И. Я. Трудовое право России. Историко-правовое исследование. М., 2001. С. 185.

${ }^{11}$ Мордачев В. Д. Законы поведения рабочей силы. Екатеринбург, 2009. С. 20. 
конодательства Союза ССР в соответствие с Конституцией СССР 1977 г. предусматривалась разработка особого закона о трудовых коллективах... В науке трудового права в тот период высказывалось множество предложений о содержании этого акта, причем большинство правоведов выступали за предоставление трудовым коллективам действенных и гарантированных полномочий по участию в управлении предприятиями (в том числе говорилось о необходимости создания СТК, выборности руководителей и т. п.). Однако такие положения в основном реализованы не были: консервативные круги, прежде всего аппарат высших государственных и общественных органов, блокировали предложения, затянув разработку законопроекта до 1983 г. ${ }^{12}$

Только 17 июля 1983 г. был принят Закон СССР «О трудовых коллективах и повышении их роли в управлении предприятиями, учреждениями, организациями» (далее - Закон от 17 июля 1983 г.).

Закон предусматривал полномочия трудовых коллективов в обсуждении и решении государственных и общественных дел, в планировании экономического и социального развития, участии в заключении коллективных договоров, обеспечении сохранности социалистической собственности и рационального использования материальных ресурсов, организации нормирования и оплаты труда, в развитии трудовой активности работников и организации социалистического соревнования, в подготовке, повышении квалификации и расстановке кадров, в распределении и использовании фондов экономического стимулирования, в улучшении условий и охраны труда, а также другие вопросы, предусмотренные законодательством о труде.

Во исполнение положений закона было издано постановление Совета Министров СССР, ВЦСПС от 10 мая 1984 г. № 429 «Об особенностях применения Закона СССР «О трудовых коллективах и повышении их роли в управлении предприятиями, учреждениями, организациями в отдельных отраслях народного хозяйства».

Важно отметить, что, несмотря на прогрессивность основных положений закона, направленных на широкое участие работников в управлении предприятиями, учреждениями и организациями, в полном объеме предусмотренные Законом от 17 июля 1983 г. полномочия реализовать было весьма затруднительно.

В связи с этим следует согласиться с тезисом А. М. Куренного о том, что одной из причин недостаточной эффрективности Закона от 17 июля 1983 г. являлся тот фракт, что «телега оказалась как бы впереди лошади» - трудовой коллектив ограниченного в правах предприятия не мог в полной мере реализовать свои полномочия ${ }^{13}$.

Важно отметить, что в середине 80-х гг. XX в. осуществлялась дальнейшая нормотворческая и организационная работа по реализации За-

${ }^{12}$ См.: Бугров Л. Ю. Свобода труда в трудовом праве России. М., 1992. С. 180.

${ }^{13}$ См.: Куренной А. М. Производственная демократия и трудовое право. М., 1989. C. 34. 
кона от 17 июля 1983 г. В данный период воздействие норм права на деятельность трудовых коллективов осуществлялось по следующим направлениям: расширялась нормативная основа такой деятельности, в частности были изменены и дополнены акты о правах профкомов, предприятиях и объединениях, предусмотрены новые полномочия коллективов в области дисциплины труда, заработной платы, бригадного подряда и т. д. ${ }^{14}$

Следует отметить, что 5 февраля 1988 г. в действовавший КЗоТ РСФСР 1971 г. была введена глава 15-А «Трудовой коллектив», детализирующая некоторые полномочия коллективов в области социально-трудовых отношений.

Вместе с тем период конца 80-х - начала 90-х гг. ХХ в. во многом ознаменован процессом сужения прав трудовых коллективов вследствие перехода страны от командно-административной к рыночной экономике ${ }^{15}$.

В частности, Закон СССР от 30 июня 1987 г. № 7284-XI «О государственном предприятии (объединении)» в ст. 7 определил правомочия совета трудового коллектива предприятия, несколько отличающиеся от содержания правомочий, определенных Законом от 17 июля 1983 г.

Еще более видоизменил правовой статус трудовых коллективов Закон РСФСР от 25 декабря 1990 г. № 445-1 «О предприятиях и предпринимательской деятельности», предусмотрев круг их прав в ст. 32.

Иными словами, трудовые коллективы продолжали обладать достаточными полномочиями только на государственных и муниципальных предприятиях, а также предприятиях, в имуществе которых вклад государства или местного Совета составлял более 50 \%.

С распадом СССР и возникновением в России стихийной рыночной экономики в 1990-е гг., несмотря на сохранение в действовавшем тогда законодательстве правового статуса трудовых коллективов, их роль и возможность участия в управлении организациями неуклонно снижалась в угоду предпринимательской (хозяйской) власти работодателя.

Итогом проводимой экономической и социальной политики явилось внесение изменений в действующее трудовое законодательство.

Так, принятый 30 декабря 2001 г. и вступивший в силу 1 февраля 2002 г. Трудовой кодекс Российской Федерации (далее - ТК РФ) уже не 110 содержал понятия и полномочий трудовых коллективов, заменив его отчасти понятием представители работников ${ }^{16}$.

Окончательно же трудовые коллективы «покинули» российское трудовое законодательство в связи с принятием Федерального закона от 30 июня 2006 г. № 90-Ф3 «О внесении изменений в Трудовой кодекс Российской Федерации, признании не действующими на территории

${ }^{14}$ См.: Бугров Л. Ю. Свобода труда в трудовом праве России. С. 181.

$15 \mathrm{O}$ внесении изменений и дополнений в Кодекс законов о труде РСФСР : закон РФ от 25 сентября 1992 г. № 3543-1 // Рос. газета. 1992. 6 окт.

${ }^{16}$ Необходимость возрождения в отечественном трудовом законодательстве понятия «трудовой коллектив» видел, в частности, Л. Ю. Бугров (см.: Бугров Л. Ю. Трудовой договор в России и за рубежом. Пермь, 2013. С. 49). 
Российской Федерации некоторых нормативных правовых актов СССР и утратившими силу некоторых законодательных актов (положений законодательных актов) Российской Федерации», на основании которого Закон СССР от 17 июля 1983 г. «О трудовых коллективах» был признан утратившим юридическую силу.

В настоящее время в действующем трудовом законодательстве право работников на участие в управлении организацией обеспечивается в рамках системы социального партнерства в сфере труда, предусмотренной ст. 23-55 ТК РФ. Участие работников в управлении организацией на основании ст. 27 ТК РФ является одной из форм социального партнерства. Содержание рассматриваемой фрормы конкретизировано в ст. 53 и 53.1 ТК РФ.

Таким образом, участие представителей работников в управлении организацией в России прошло длительную эволюцию, обусловленную историческими, политическими, соџиально-экономическими факторами, от широкого участия до фактически полного отсутствия в период тотального политического режима и последующего постепенного возрождения в дальнейшем.

Перлский нащиональньй исследовательский политехнический университет, Перлский фбилиал Российской акаделии народного хозяйства и государственной службы при Президенте Российской Федерации

Кудрин А. С., кандидат юридических наук, доцент кафедры "Философия и право"

E-mail: antoune@yandex.ru
Perm National Research Polytechnic University, Perm Branch of the Russian Academy of National the Economy and Public Administration

Kudrin A. S., Candidate of Legal Sciences, Associate Professor of the Philosophy and Law Department

E-mail:antoune@yandex.ru 